\title{
LA CENSURA Y PUBLICACIÓN DE LOS VIAJES DE ENRIQUE WANTON AL PAÍS DE LAS MONAS: NUEVOS DATOS SOBRE UN TEXTO UTÓPICO-SATÍRICO DEL SIGLO XVIII
}

\author{
The Censorship and Publication of the Viajes \\ de Enrique Wanton al país de las monas: New Details \\ of an Eighteenth-Century Utopian Satirical Text
}

\author{
Carla ALMANZA-GÁLVEZ \\ Investigadora independiente
}

Fecha de recepción: 10/05/2019

Fecha de aceptación definitiva: 01/10/2019

RESUMEN: El objetivo principal de este artículo es el análisis de los documentos de la censura gubernamental de los cuatros volúmenes que conforman los Viajes de Enrique Wanton al país de las monas, obra utópico-satírica escrita entre 1769 y 1778 por el abogado y hombre de letras español Gutierre Joaquín Vaca de Guzmán. Este estudio no solo contribuye a un mejor conocimiento de la producción editorial de un texto que fue un rotundo éxito de ventas durante la Ilustración española, pese a haberse originado a partir de la traducción y adaptación de la obra del autor italiano Zaccaria Seriman, sino que también muestra la importancia de la tradición utópica de la España ilustrada, significativamente representada por la obra de Vaca de Guzmán.

Palabras clave: utopismo; sátira social; censura civil; Gutierre Vaca de Guzmán; Zaccaria Seriman; Jonathan Swift.

ABSTRACT: The main objective of this article is to analyse the documents concerning government censorship of the four volumes that make up the Viajes de 
Enrique Wanton al país de las monas, a utopian satirical work written between 1769 and 1778 by the Spanish lawyer and man of letters Gutierre Joaquín Vaca de Guzmán. This study not only contributes to a better understanding of the editorial production of a text that was a resounding best seller during the Spanish Enlightenment, despite having originated from the translation and adaptation of the work by the Italian author Zaccaria Seriman, but also shows the importance of the utopian tradition of enlightened Spain, significantly represented by the work of Vaca de Guzmán.

Key words: utopianism; social satire; civil censorship; Gutierre Vaca de Guzmán; Zaccaria Seriman; Jonathan Swift.

\section{INTRODUCCIÓN}

En el contexto de la circulación de ideas característica del espíritu cosmopolita de la época de las Luces en España, todo texto publicado estuvo sometido en primer lugar a la criba de la censura civil. Antes de ser entregados a la imprenta, todos los libros eran examinados por calificadores nombrados por el Gobierno para censurar cualquier contenido que pudiera constituir una afrenta o peligro para la institución monárquica, la Iglesia o la moral. Un conjunto peculiar de textos literarios de la época pertenecientes al modelo cuestionador del género utópico debió haber sido visto como un potencial foco de ideología disidente del sistema. Entre ellos destacan los Viajes de Enrique Wanton al país de las monas ${ }^{1}$ y su respectivo Suplemento, una obra que se caracteriza no solo por su intento de promover una mejora social mediante el retrato satírico de la sociedad de la época, sino también por su exitosa recepción entre el público lector y su consiguiente consagración como uno de los libros de mayor demanda en su tiempo.

El presente trabajo se centra en la documentación en torno de la censura gubernamental de esta obra de cuatro volúmenes y escrita en la segunda mitad del siglo XVIII por el casi desconocido autor español Gutierre Joaquín Vaca de Guzmán y Manrique (1733-1804) -a menudo confundido con su hermano José María Vaca de Guzmán (1744-h. 1816), un reconocido poeta y crítico literario a quien con frecuencia se atribuye la autoría de los Viajes-. El estudio de dicho material, perteneciente al Archivo Histórico Nacional y a la Real Academia de la Historia en Madrid, permitirá evaluar el significado e impacto de la sátira social de la obra desde la perspectiva de las autoridades censoras. Antes de analizar la valoración y recepción del texto, será necesario discutir sus particularidades formales e ideológicas en el marco del pensamiento ilustrado de la época y de la tradición utópica europea.

1. El título completo es Viajes de Enrique Wanton a las tierras incógnitas australes y al país de las monas, en donde se expresan las costumbres, carácter, ciencias y policía de estos extraordinarios habitantes. Traducidos del idioma inglés al italiano, y de este al español, por D. Joaquín de Guzmán y Manrique. Con láminas que representan algunos pasajes de la bistoria. 


\section{PRODUCCIÓN Y CARACTERIZACIÓN DEL TEXTO}

La complejidad de la publicación e historia bibliográfica de los Viajes de Enrique Wanton se deriva de la naturaleza intrincada de su composición. Los dos primeros volúmenes son la traducción española hecha por el abogado y escritor sevillano Gutierre Vaca de Guzmán del texto original italiano de Zaccaria Seriman, aparecido en Venecia en $1749^{2}$, y fueron publicados en 1769 y 1771 respectivamente $^{3}$. Los dos volúmenes siguientes se publicaron en 1778 con el título Suplemento de los viajes de Enrique Wanton al país de las monas y son creación del propio Vaca de Guzmán, no una traducción de la continuación de la obra escrita por Seriman también en otros dos tomos en $1764^{4}$. Un aparente error de imprenta resultó en la existencia de copias del cuarto volumen publicadas presuntamente en 1771, las cuales aparecen en catálogos de bibliotecas en Madrid, Zaragoza, Oviedo, Tarragona y Pamplona. Puesto que la portada y la impresión de la supuesta edición de 1771 son idénticas a las de una edición posterior del mismo tomo hecha en 1781, es razonable pensar que la confusión se haya debido a una errata producida en dichos ejemplares en cuanto al año real de impresión de 1781. Con respecto al nombre del autor español, como advirtiera Juan Sempere y Guarinos $^{5}$, este suele aparecer en las portadas de la obra como Joaquín de Guzmán y Manrique, pero el propio autor emplea las iniciales de su nombre completo al final del respectivo prólogo de cada volumen.

El primer volumen traducido se terminó de escribir en 1768, año en que Vaca de Guzmán solicita al Consejo de Castilla la licencia de impresión para poder publicarlo ${ }^{6}$. Este aspecto pone a los Viajes en clara vinculación con la orientación satírico-social de otras publicaciones de la época, sobre todo de $E l$ Pensador, uno de los periódicos más influyentes de la década de $1760^{7}$. En realidad, parece que el autor estuvo siempre interesado en tener pleno control sobre la producción y difusión de su texto, determinando quién debía imprimirlo y

2. SERIMAN, Zaccaria. Viaggi di Enrico Wanton alle terre incognite australi, ed al paese delle scimmie, ne' quali si spiegano il carattere, li costumi, le scienze, e la polizia di quegli straordinari abitanti. Tradotti da un manoscritto inglese, con figure in rame. Venecia: Giovanni Tagier, 1749, 2 vols.

3. La descripción del primer volumen aparece en Gaceta de Madrid, n. ${ }^{\circ} 32,8$ de agosto de 1769 , pp. 257-264 (p. 264), y la del segundo volumen en Gaceta de Madrid, n. ${ }^{\circ} 44,29$ de octubre de 1771, pp. 371-382 (p. 382).

4. Se anuncia la aparición del tercer volumen en Gaceta de Madrid, n. ${ }^{\circ}$ 9, 3 de marzo de 1778, pp. 77-88 (p. 88), y la del cuarto volumen en Gaceta de Madrid, n. ${ }^{\circ} 35$, 30 de abril de 1779, pp. 293-300 (p. 300).

5. Sempere y GuARINos, Juan. Ensayo de una biblioteca española de los mejores escritores del reinado de Carlos III. Madrid: Imprenta Real, 1789 (Madrid: Gredos, 1969, edición facsímil), vol. VI, p. 114.

6. Archivo Histórico Nacional, Consejos, legajo 50662, licencia de impresión del primer tomo de los Viajes de Enrique Wanton al país de las monas. Madrid, 17 de agosto de 1768.

7. Guinard, Paul-Jacques. La Presse espagnole de 1737 à 1791: formation et signification d'un genre. París: Centre de Recherches Hispaniques, Institut d'Études Hispaniques, 1973, pp. 125-215. 
cediendo la exclusividad de la venta de ejemplares al librero Bernardo Alberá hasta 1785. Este afán de control, así como de enriquecerse, podría sustentarse en la posibilidad de que Vaca de Guzmán haya poseído las láminas que se usarían para ilustrar las posteriores ediciones de la obra. Las imágenes fueron elaboradas por el grabador madrileño José Patiño y representan algunas escenas de la narración en las que aparecen monos antropomorfizados vestidos al estilo dieciochesco. El número de ilustraciones es mayor en el texto original italiano, el cual incluye hasta más de treinta grabados en algunas ediciones.

La mayoría de los viajes imaginarios que se escribieron a partir del siglo XVII siguen un modelo narrativo similar, el cual puede apreciarse en las convenciones del género aprovechadas por Seriman y consecuentemente por Vaca de Guzmán. Más específicamente, los Viajes de Enrique Wanton fueron inspirados en gran medida por Los viajes de Gulliver (Gulliver's Travels) ${ }^{8}$, obra del escritor anglo-irlandés Jonathan Swift que fue publicada anónimamente en 1726. Su influencia es visible tanto en los elementos literarios de la historia como en la postura satírica que estructura una intensa reflexión crítica sobre el estado de las instituciones sociales, culturales y políticas de la nación española. De hecho, una reseña del primer volumen de la primera traducción española de Los viajes de Gulliver que apareció en el Memorial Literario en 1794 comparaba la obra de Swift con la de Vaca de Guzmán:

La historia de los viajes del Capitán Lemuel Gulliver es una invectiva de la misma especie que los viajes de Enrique Wanton al país de las Monas, el viaje a la luna de Cirano de Barbeirac [sic], del Saturnino Micromegas y otros?

La célebre novela de Swift es fundamentalmente una sátira acerca de la naturaleza humana y el comportamiento social, plasmada en la representación paródica de las deficiencias y limitaciones de la sociedad inglesa del siglo XVIII. En tal sentido, el sistema social satirizado que presenta Vaca de Guzmán en su obra no solo corresponde a la actitud crítica de los pensadores ilustrados españoles hacia su propia nación, sino que emula también la postura de Swift hacia Inglaterra y la cultura occidental.

A semejanza de Los viajes de Gulliver, la historia de los Viajes de Enrique Wanton empieza con una descripción biográfica del protagonista y sus circunstancias familiares ${ }^{10}$. Enrique Wanton es un inglés que, al igual que Lemuel Gulliver, está

8. El título completo es Travels into Several Remote Nations of the World. In Four Parts. By Lemuel Gulliver, First a Surgeon, and Then a Captain of Several Ships (Viajes por varias naciones remotas del mundo. En cuatro partes. Por Lemuel Gulliver, primero cirujano y luego capitán de varios navíos).

9. Continuación del Memorial Literario, Instructivo y Curioso de la Corte de Madrid, febrero de 1794, pp. 161-239 (p. 216).

10. No es la intención de este artículo ofrecer un análisis detallado de los cuatro volúmenes que componen la obra. Para un enfoque más amplio y pormenorizado, ver nuestro estudio del texto 
destinado a vivir de una profesión que realmente no le interesa y que solo le produce infelicidad. Con el fin de escapar de su insatisfactoria realidad, Enrique decide abandonar su patria y emprender un arriesgado viaje a las Indias Orientales, en el cual conoce a Roberto, un joven comerciante inglés que se encontraba en un viaje de negocios en representación de su padre. Se desarrolla entonces una fuerte amistad entre los dos jóvenes, quienes conforman una especie de dúo cervantino cuya interacción es la de un maestro y su discípulo. De hecho, tras el naufragio de su embarcación, el relato de viaje imaginario adquiere rasgos de la novela de formación o aprendizaje (Bildungsroman) en tanto que el temor instintivo de Enrique ante la nueva realidad que empezarán a descubrir es progresivamente superado gracias a la iluminadora y práctica orientación de Roberto. Los náufragos viven por varios meses en un territorio ignoto que identifican con la mítica región del hemisferio sur conocida como Terra Australis Incognita o "Tierra Desconocida del Sur». Sin embargo, su suerte cambia el día en que accidentalmente llegan al país de los monos, el cual alberga una sociedad que parodia satíricamente el estilo de vida europeo -específicamente español en la traducción de Vaca de Guzmán- de aristócratas e intelectuales. Desde este momento, la visión lógica y racional del mundo convencionalmente aceptada es subvertida en el relato. La inversión irónica consiste en que los jóvenes viajeros son tratados como criaturas exóticas y ridículas en un mundo dominado por seres considerados normalmente inferiores.

El conflicto entre los conceptos de civilización y barbarie es constantemente aludido en las ideas expresadas por Enrique y Roberto, sobre todo cuando declaran sentirse privilegiados por haber sido dotados con la capacidad de razonar, lo cual es justamente el motivo por el que los monos desconfían de ellos. Si el poder de Gulliver radica en su superioridad física ante los liliputienses, la fortaleza de los dos viajeros europeos reside en su facultad de razonamiento y en la tenencia de armas de fuego que les permitan defenderse en situaciones de peligro. Aunque no están desprovistos de deseos y pasiones, sus acciones se ajustan a los dictados de la razón y de Dios. El inconveniente de los supuestos beneficios de una racionalidad superior es la posible deshumanización que acarrea cualquier sistema social dirigido por el ideal de un conocimiento racional perfecto. No obstante, Enrique y Roberto no pretenden validar su posición de dominio en función de lo favorable de sus habilidades, sino de la sabiduría de la que los provee su amistad. La amistad y la búsqueda de la felicidad fueron ideales importantes del pensamiento ilustrado pues eran vistos como motores para el desarrollo de la humanidad.

La discusión en torno del concepto de civilización en los Viajes se enfoca en la crítica de costumbres sociales, no de estructuras políticas. Durante la Ilustración, el nuevo significado de civilización estaba estrechamente vinculado al refinamiento del comportamiento social:

en AlmanZA-Gálvez, Carla. Form and Reform in Eighteenth-Century Spain: Utopian Narratives and Socio-Political Debate. Cambridge, Reino Unido: Legenda, 2019, pp. 87-118. 
La acción de refinar y mejorar las costumbres de un pueblo se entiende [...] como progreso de la moral social, expresión ideológica de una nueva moralidad ilustrada y revolucionaria. Es una acción moral dirigida al perfeccionamiento de la sociedad civil a lo largo del desarrollo histórico de la humanidad. [...] Es decir que el concepto dieciochesco de civilisation se construye sobre la base semántica establecida por las virtudes civiles propias de la nueva sociedad burguesa ${ }^{11}$.

A lo largo de los cuatro volúmenes de la versión española de los Viajes, es evidente la preocupación por las tradiciones y costumbres de la época -tema recurrente de la prensa reformista española de la segunda mitad del siglo XVIII-, así como el objetivo de demostrar los peligros que un refinamiento extremo podría significar para la sociedad civil. Es en tal sentido que la obra ha sido considerada, por algunos críticos, como una expresión rudimentaria de la corriente literaria costumbrista del siglo XIX ${ }^{12}$.

Un aspecto fundamental es la distinción entre el espacio de la urbe y el del campo, y sus respectivos habitantes. Según la perspectiva del protagonista, la influencia negativa de la mentalidad extranjerizante de los monos de la metrópoli, es decir, de la capital llamada Simiópolis, corrompe a los monos de las regiones periféricas. Por tanto, el intercambio de costumbres y valores entre la capital y las provincias resulta esencialmente perjudicial y demuestra el efecto degenerativo que comportamientos supuestamente más civilizados ejercen en un espacio regido por una conciencia natural. El deplorable estado cultural del centro urbano es el resultado de fomentar la injerencia del conocimiento foráneo en el ámbito de las artes y las ciencias:

Se ha introducido entre los Simiopolitanos el fanatismo de no dar estimación sino a las cosas que vienen de lejos. Los profesores de las ciencias, que se aprenden en esta ciudad, no tienen mérito; para que sean estimados, es necesario que vengan de países extranjeros, y a proporción de la distancia de nuestra patria crece la reputación que de ellos se forma: no se cree poder hallar artífices excelentes sino fuera de estos dominios; lo propio se entiende de músicos, pintores y de todos aquellos que se emplean en cualquier ciencia, o arte liberal o mecánico. Esta necedad se extiende a todas las cosas; [...] el dinero sale del Estado, que por consiguiente se va empobreciendo; y entretanto los forasteros se ríen y triunfan de nuestra ignorancia ${ }^{13}$.

11. Escobar, José. "Más sobre los orígenes de civilizar y civilización en la España del siglo XVIII». Nueva Revista de Filología Hispánica, 1984, 33, pp. 88-114 (pp. 90-91).

12. Escobar, José y Percival, Anthony. «Viaje imaginario y sátira de costumbres en la España del siglo XVIII: los Viajes de Enrique Wanton al país de las monas". En HINTERHÄUSER, Hans; RÖSSNER, Michael y WaGNER, Birgit (eds.). Aufstieg und Krise der Vernunft: Komparatistische Studien zur Literatur der Aufklärung und des Fin-de-Siècle. Viena: Hermann Böhlaus Nachfolger, 1984, pp. 79-94 (pp. 83-84).

13. SERIMAN, Zaccaria. Viajes de Enrique Wanton al país de las monas. Trad. [Gutierre] Joaquín [Vaca] de Guzmán y Manrique. Madrid: Imprenta de Pantaleón Aznar, 1771, vol. II, pp. 152-153. 
La indiferencia ante el potencial intelectual y cultural de la sociedad simiesca termina por conducirla hacia su autodestrucción. La crítica costumbrista fue una herramienta ideológica utilizada por la minoría intelectual ilustrada en España para satisfacer su deseo de reformar un estilo de vida español que consideraba sumido en un estado necesitado de transformación social.

No solo la exitosa recepción de su traducción por los lectores, sino también su interés por retratar críticamente la experiencia social española, llevaron a Vaca de Guzmán a componer dos volúmenes con su propia continuación de la historia escrita por Seriman, en lugar de traducir los siguientes dos volúmenes en los que Seriman continuaba la historia del país de los monos con la visita de Enrique al país de los cinocéfalos o seres con cabeza de perro ${ }^{14}$. Debido a la censura de su obra en Italia, Seriman decidió publicar los dos tomos de la continuación en una edición que incluía los dos volúmenes previos con un falso pie de imprenta en Berna en $1764^{15}$. Una situación similar a la traducción y continuación española de los Viajes, coincidentemente o no, ocurrió con la traducción francesa de Los viajes de Gulliver hecha por Pierre Desfontaines, quien añadió un quinto viaje adicional a los cuatro viajes originalmente escritos por Swift. La primera traducción española del libro de Swift, realizada por Ramón Máximo Spartal entre 1793 y 1800, se basa en la edición francesa e incluye la continuación creada por Desfontaines, que se titula Le Nouveau Gulliver, ou voyage de Jean Gulliver, fils du capitaine Gulliver (El nuevo Gulliver, o el viaje de Juan Gulliver, bijo del capitán Gulliver) y que narra el viaje del hijo de Lemuel Gulliver $^{16}$. Aunque, en el nivel ficcional, Vaca de Guzmán justifica la creación de su Suplemento alegando que su texto se basa en un manuscrito que Seriman no encontró y en el cual Enrique narra la continuación de sus vivencias en el país de los monos, el propósito de la composición de los dos volúmenes adicionales es enfatizar el enfoque crítico de los códigos morales y sociales españoles mediante la narración de la amistad que se desarrolla entre Enrique y Tulipán, el hijo menor del protector de Enrique en la nación simiesca. Vaca de Guzmán subraya la dimensión ética de la sociedad de los monos a través de las reflexiones que hace Enrique sobre sus costumbres y de las observaciones de Roberto en cuanto a su sistema político.

14. SERIMAN, Zaccaria. Viaggi di Enrico Wanton alle terre incognite australi, ed ai regni delle scimmie, e dei cinocefali, nuovamente tradotti da un manoscritto inglese. Berna: s. i., 1764, 2 vols.

15. Morange, Claude. "Variations sur un thème: le monde rural dans le Suplemento [...] de los viages de Enrique Wanton (1778)». En Serrano, Carlos; Duviols, Jean-Paul y Molinié, Annie (eds.). Les Voies des Lumières: le monde ibérique au xvIIIe siècle. París: Presses de l'Université de Paris-Sorbonne, 1998, pp. 79-111 (p. 80).

16. DEACON, Philip. "La novela inglesa en la España del siglo XVIII: fortuna y adversidades». En García Lara, Fernando (ed.). Actas del I Congreso Internacional sobre Novela del Siglo XVIII. Almería: Universidad de Almería, 1998, pp. 123-139 (p. 133). 
El Suplemento cuestiona los fundamentos de diversos aspectos sociales, tales como la vida de la corte, la extravagancia y el lujo, el sistema legal, ciertos tipos sociales como los pretendientes y petimetres, el estado de la educación, la función de las universidades, las falsas creencias, las tertulias, el comportamiento y los privilegios de la nobleza, la ociosidad, entre otros factores. Todos estos asuntos, por lo demás, aparecen en las críticas sociales de los reformistas españoles, especialmente en las obras periódicas ${ }^{17}$. La ruptura sistemática entre el centro y la periferia se manifiesta en el personaje de Tulipán. La relación de Enrique con Tulipán no solo es similar a la amistad didáctica entre Enrique y Roberto, sino que es también una herramienta cognitiva por medio de la cual Enrique puede mejorar su conocimiento de los habitantes de la capital al verlos interactuar con Tulipán. La caracterización del joven mono corresponde, en cierto modo, a la figura literaria del petimetre, frecuentemente empleada por los escritores satíricos españoles del siglo XVIII ${ }^{18}$. Este tipo social es criticado por su afán de imitar costumbres extranjeras con el fin de diferenciarse de sus compatriotas. Según su mentalidad, ser civilizado significa abandonar costumbres ancestrales e incultas para alcanzar la sofisticación de comportamientos más modernos:

[Los jóvenes simiopolitanos] no son buenos para otra cosa que para ir de estrado en estrado trayendo y llevando chismes con otros como ellos; para andar de baile en baile, donde sueltan los diques a su desenfreno; para marchar por esas calles con el mayor atolondramiento; y en fin para aprender y ejecutar con gran estudio cuantas gesticulaciones ven a los extranjeros, [...] haciendo en todo un increíble esfuerzo para diferenciarse del resto de sus compatriotas ${ }^{19}$.

La rusticidad es asociada con una España antigua que se contrapone al refinamiento social de la Europa actual. En última instancia, la sátira de Vaca de Guzmán curiosamente condena la práctica de actitudes cosmopolitas en tanto que dificulta la afirmación del carácter español. Dado este manifiesto cosmopolitismo, la tierra imaginaria de los monos actúa como un espejo en el cual toda la sociedad europea puede reconocer y expiar la irracionalidad de sus vicios. Con la finalidad de criticar este espíritu de desarraigo alienante, pero también con el objetivo de evitar la posible censura de su obra debido a la crítica directa de la sociedad española, Vaca de Guzmán elabora una representación satírica del conflicto ideológico ocasionado por la asimilación indiscriminada de convenciones sociales foráneas, muchas de las cuales son consideradas cuestionables. La interpretación de costumbres y modos de pensar llevada a cabo por los viajeros ingleses se enmarca en la visión de un reformismo crítico basado en lo que se ajusta a la razón y típico del

17. Guinard. La Presse espagnole de 1737 à $1791 \ldots$, pp. 413-426, 441-457, 466-470, 473-480.

18. Ver Penrose, Mehl. «Petimetres as a Third Sex in José Clavijo y Fajardo's El pensador matritense». Dieciocho, 2009, 2, pp. 351-364.

19. [VACa] De GuZmán y ManRiQue, [Gutierre] Joaquín. Suplemento, o sea tomo tercero de los viajes de Enrique Wanton al país de las monas. Madrid: Antonio de Sancha, 1778, p. 29. 
pensamiento social ilustrado. La contribución de los Viajes consiste en concienciar al pueblo español sobre la decadencia creciente de sus prácticas sociales debido a la superficialidad de sus supuestas costumbres civilizadas.

Los elementos satíricos y didácticos del texto de Vaca de Guzmán no impiden que la historia desarrolle una visión utópica como contrapartida de la realidad observada por Enrique. El espacio predominantemente antiutópico que constituye el país de los monos empieza a vislumbrarse como una posible utopía cuando Enrique visita una ciudad en el sur del país que es descrita como un próspero centro burgués y que puede ser identificada con la ciudad española de Cádiz ${ }^{20}$. La existencia de un estilo de vida simultáneamente acomodado y modesto en un contexto burgués hace posible concebir a la nación de los monos como una sociedad utópica. La fortuna adquirida gracias al esfuerzo personal es beneficiosa para el país entero ya que contribuye a la creación de puestos de trabajo y a la circulación de dinero: "[E]llos eran los que tenían el dinero del reino, adquirido a fuerza de su industria y de los peligros a que se exponían continuamente» ${ }^{21}$.

El país de los monos no es, entonces, una distopía porque se discuten aspectos tanto positivos como negativos de su sociedad. En todo caso, se aprecia una constante tensión utópica y distópica en los diferentes espacios urbanos en los que se examinan las costumbres de sus habitantes ${ }^{22}$. Asimismo, la obra de Vaca de Guzmán reafirma la flexibilidad del modelo narrativo utópico, el cual, en cierta medida, se funda en la dialéctica entre utopía y distopía, tal como ocurre en la sátira de la sociedad inglesa presentada por Swift en Los viajes de Gulliver ${ }^{23}$. Si bien el texto fundacional del género utópico fue la aclamada Utopía (1516) de Thomas More, en donde el político y humanista renacentista inglés establece los lineamientos de una sociedad imaginaria ideal regida por la felicidad, la prosperidad y el bienestar ${ }^{24}$, los Viajes se inscriben en la tradición utópica instaurada por Swift y consistente en el realce satírico del modelo utópico ${ }^{25}$. Aun cuando la estructura de base es la obra de

20. EsCOBAR y PeRCIVAL. "Viaje imaginario...., p. 89.

21. [VACA] De GuZmán y ManRiQue, [Gutierre] Joaquín. Suplemento, o sea tomo cuarto y último de los viajes de Enrique Wanton al país de las monas. Madrid: Antonio de Sancha, 1778, p. 118.

22. Para un acercamiento general a las tradiciones narrativas utópicas y distópicas, ver ClaEYs, Gregory (ed.). The Cambridge Companion to Utopian Literature. Cambridge, Reino Unido: Cambridge University Press, 2010.

23. Sobre la flexibilidad del género utópico, ver Morson, Gary Saul. The Boundaries of Genre: Dostoevsky's Diary of a Writer and the Traditions of Literary Utopia. Evanston, Illinois: Northwestern University Press, 1981; y Roemer, Kenneth M. Utopian Audiences: How Readers Locate Nowhere. Amherst; Boston: University of Massachusetts Press, 2003.

24. Ver BAKer-Smith, Dominic. More's Utopia. Londres: HarperCollins Academic, 1991.

25. Robert Elliott sostiene que "Satire and utopia are not really separable, the one a critique of the real world in the name of something better, the other a hopeful construct of a world that might be. The hope feeds the criticism, the criticism the hope» "La sátira y la utopía no son realmente separables, una es una crítica del mundo real en nombre de algo mejor, la otra una creación esperanzadora de un mundo que podría ser. La esperanza alimenta la crítica, la crítica la esperanza») (ELLIOTT, Robert C. The Shape of Utopia: Studies in a Literary Genre. Chicago; Londres: University of Chicago Press, 1970, p. 24). 
More -de hecho, el tercer volumen del Suplemento contiene una referencia explícita al autor inglés: "No adquirió tanto crédito para con patricios y extranjeros el incomparable Tomás Moro entre las felicidades de su libertad como entre los horrores de su prisión» ${ }^{26}$, Vaca de Guzmán se revela como un innovador literario con una fuerte vena satírica y humorística.

El hecho de que la obra haya tenido múltiples reediciones en un período de más de setenta años y de que no haya pasado desapercibida en los comentarios de importantes figuras españolas del costumbrismo literario de inicios del siglo XIX, como Mariano José de Larra y Ramón de Mesonero Romanos ${ }^{27}$, demuestra que logró cautivar plenamente la imaginación de los lectores. Donald White y Philip Gove dan cuenta de cinco ediciones de la obra de Vaca de Guzmán entre 1769 y $1831^{28}$, Francisco Aguilar Piñal consigna una edición publicada en $1846^{29}$ y José Montesinos añade otra posterior en $1871^{30}$. Las ilustraciones que acompañan a la narración en cada uno de los volúmenes tuvieron una acogida tan positiva entre los lectores que en 1800 la Imprenta Real preparó una edición especial que contenía dieciséis nuevos grabados hechos por el artista valenciano Miguel Gamborino ${ }^{31}$.

\section{LABOR CENSORA Y VALORACIÓN TEXTUAL}

La censura ideológica de la producción intelectual y cultural en el siglo XVIII dependía, en primera instancia, de la aprobación concedida por el Juzgado de Imprentas del Consejo de Castilla, órgano que otorgaba las licencias de impresión a los textos cuyos autores o impresores solicitaban permiso para su respectiva

26. [VACA] DE GUZMÁn y MANRIQUE. Suplemento, o sea tomo tercero..., p. 191.

27. LARRA, Mariano José de. "Panorama matritense". Cuadros de costumbres de la capital observados y descritos por un Curioso Parlante. Artículo segundo y último». En Pérez Vidal, Alejandro (ed.). Fígaro: colección de artículos dramáticos, literarios, políticos y de costumbres. Barcelona: Crítica, 1997, pp. 544-548 (p. 545); Mesonero Romanos, Ramón de. Panorama matritense. Cuadros de costumbres de la capital, observados y descritos por un Curioso Parlante. Madrid: Imprenta de Repullés, 1835, vol. I, p. xi. Ver también Mesonero Romanos, Ramón de. "Memorias de un setentón». En Seco Serrano, Carlos (ed.). Obras de Ramón de Mesonero Romanos. Madrid: Atlas, 1967, vol. V, pp. 1-247 (p. 187).

28. White, Donald Maxwell. Zaccaria Seriman (1709-1784) and the Viaggi di Enrico Wanton: A Contribution to the Study of the Enlightenment in Italy. Manchester, Reino Unido: Manchester University Press, 1961, pp. 141-149; Gove, Philip Babcock. The Imaginary Voyage in Prose Fiction. Londres: Holland Press, 1961, pp. 314-315.

29. Aguilar Piñal, Francisco. Bibliografía de autores españoles del siglo XVIII. Madrid: Consejo Superior de Investigaciones Científicas, 1995, vol. VIII, p. 238.

30. Montesinos, José F. Introducción a una bistoria de la novela en España en el siglo XIX. Valencia: Castalia, 1972, p. 246.

31. La portada de esta edición solo especifica que los cuatro volúmenes podían adquirirse en la librería de Gabriel Gómez. La descripción detallada de la edición en el semanario londinense Times Literary Supplement de 1923, en donde se comparan las ilustraciones de Miguel Gamborino con las acuarelas de Francisco de Goya, puede verse en WhiTe. Zaccaria Seriman..., p. 148. 
publicación ${ }^{32}$. Tras salir los libros de la imprenta, y en caso de recibir una denuncia, el Santo Oficio de la Inquisición era la entidad encargada de prohibir o permitir su circulación pública ${ }^{33}$. Debido a cierta coyuntura política e institucional, el Consejo propuso reformar el sistema de concesión de licencias de impresión en 1770 , pero tal proyecto de reforma no llegó a concretarse ${ }^{34}$. Es en este contexto de control sobre el pensamiento y de vigilancia o manipulación de la experiencia receptora del público lector en el que debe examinarse la documentación de censura previa en torno de los Viajes, la cual fue realizada principalmente por los censores de la Real Academia de la Historia en Madrid, una institución "garante de las decisiones del poder, ${ }^{35}$.

Fray Alonso de Mira fue el primero en actuar como censor gubernamental de la traducción del primer volumen hecha por Vaca de Guzmán. En su informe de agosto de 1768, en donde concede la correspondiente licencia para la impresión de dicho volumen solicitada por el apoderado del autor, José Antonio Sanz, el fraile carmelita elogia las cualidades no solo estéticas sino también éticas de los Viajes. Fray Mira califica la primera parte de la obra como "curiosa invectiva» y destaca las habilidades lingüísticas mediante las cuales Vaca de Guzmán no solo da a conocer el importante trabajo de Seriman en el contexto español, sino que logra superar la destreza narrativa del texto original ${ }^{36}$ :

Obedeciendo el superior orden de Vuestra Alteza, he visto el libro intitulado Viajes de Enrique Wanton a las tierras incógnitas australes y, habiéndole leído con singular cuidado y especialísimo gusto, no he hallado en el traducido del italiano al español por don Joaquín de Guzmán y Manrique voz, cláusula, ni proposición alguna que ofenda la pureza de nuestra fe católica, buenas costumbres ni pragmáticas reales. Si bien he hallado que el elocuente y discreto traductor don Joaquín de Guzmán y Manrique se ha merecido con el trabajo de la traducción de este libro nuestro aplauso, nuestra gratitud y reconocimiento no solo porque nos ha abierto un libro que para nosotros estaba cerrado, sino porque, en la traducción de esta curiosa invectiva, se ha hecho acreedor de aquella misma gloria que se adquieren los artífices más famosos en la artificiosa labor de los metales preciosos y exquisitos, que no dando a estos ni la esencia ni la naturaleza les dan con su artificiosa industria

32. Para una consideración general de la actividad censora del Consejo de Castilla durante el reinado de Carlos III, ver Domergue, Lucienne. Censure et Lumières dans l'Espagne de Charles III. París: Éditions du CNRS, 1982.

33. Ver Defourneaux, Marcelin. Inquisición y censura de libros en la España del siglo XVIII. Trad. José Ignacio Tellechea Idígoras. Madrid: Taurus, 1973.

34. Velasco, Eva. «Fundamentos históricos y principios ideológicos del proyecto de reforma del sistema de censura previa en 1770». Cuadernos Dieciochistas, 2003, 4, pp. 123-134 (pp. 124-125).

35. Velasco, Eva. "Las censuras de la Real Academia de la Historia». En Durán López, Fernando (ed.). Instituciones censoras: nuevos acercamientos a la censura de libros en la España de la Ilustración. Madrid: Consejo Superior de Investigaciones Científicas, 2016, pp. 113-158 (p. 128).

36. Para mayor claridad, se han modernizado la ortografía y la puntuación en todos los extractos de los manuscritos citados en este artículo. 
la pureza, el esplendor y la hermosura, y nuestro elocuente traductor, con la viveza en el decir y lo decente, decoroso, claro e insinuativo de nuestro idioma español, le ha dado mejor lustre y mejor alma que la que le dio el autor en la lengua natural materna $^{37}$.

Es relevante observar que el fraile censor demanda que la impresión del libro "se haga en papel fino y de buena estampa»" lo que indica su reconocimiento de la calidad e importancia del texto al requerir que sea impreso en un formato elegante y duradero. Como se sabe, el Consejo de Castilla pedía que los libros cumplieran con los más altos estándares de producción cuando los consideraba valiosos y susceptibles de atraer la atención de lectores que tuvieran la capacidad económica de adquirirlos ${ }^{39}$.

En 1770, otro apoderado del autor español, José de la Cámara Martínez, solicita el permiso para la impresión de la traducción del segundo volumen de los Viajes. En enero de 1771, el escribano de cámara del Consejo de Castilla Ignacio de Igareda remite el manuscrito de dicho volumen a la Real Academia de la Historia para su censura, al tiempo que adjunta también un ejemplar impreso del primer volumen para que el correspondiente revisor pueda tener una mejor comprensión de toda la traducción, indicando que la censura de la primera parte de la obra estuvo a cargo del padre Mira $^{40}$. Se incluye asimismo en este expediente el informe de censura favorable de Martín Martínez, miembro de la Real Academia de la Historia, quien insinúa que la obra de Seriman había llegado a ser un éxito de ventas en España y que, de hecho, la traducción de Vaca de Guzmán serviría para aclarar y enriquecer ciertas vaguedades u oscuridades presentes en el texto italiano:

El original de esta obra ha mucho tiempo que es conocido y celebrado en España, con sentimiento de que su idea no fue enteramente concluida, por lo cual no hay reparo alguno en que el Consejo dé licencia para que se publique su traducción ${ }^{41}$.

La licencia de impresión del segundo volumen fue concedida el 18 de febrero de 1771 tras la aprobación de José Miguel de Flores, director de la revista literaria Aduana Crítica: Hebdomadario de los Sabios de España (1763-1765) y secretario

37. Archivo Histórico Nacional, Consejos, legajo 50662, licencia de impresión del primer tomo de los Viajes de Enrique Wanton al país de las monas. Madrid, 19 de agosto de 1768.

38. Ibid.

39. Ver Rumeu de ARmas, Antonio. Historia de la censura literaria gubernativa en España: historia, legislación, procedimientos. Madrid: M. Aguilar, 1940.

40. Archivo Histórico Nacional, Consejos, legajo 5570, expediente 46, licencia de impresión del segundo tomo de los Viajes de Enrique Wanton al país de las monas. Madrid, 8 de enero de 1771.

41. Real Academia de la Historia, Ms. 11/8013, n. ${ }^{\circ} 47$, revisión de los Viajes de Enrique Wanton al país de las monas. Madrid, 7 de febrero de 1771, fol. 2 r. 
perpetuo de la Real Academia de la Historia ${ }^{42}$. Es interesante observar que, en el borrador de la censura escrito por Flores, este hace referencia a enmiendas y sugerencias que supuestamente habían sido hechas al primer volumen de la obra durante anteriores procesos de revisión para la concesión de las licencias de impresión solicitadas:

[A]cordó se devuelvan al Consejo para que si es de su real agrado le dé al traductor la licencia que pretende con las prevenciones expuestas en la censura de los 5 tomos anteriores de esta obra y con tal que en el $60^{\circ}$ se suprima el $\S \&^{a}[$ los símbolos indican la parte del texto que debe ser suprimida] y en el $7 .^{\circ}$ se rectifiquen las voces técnicas consultando el que lo ha traducido a un profesor de química ${ }^{43}$.

En 1777, nuevamente José de la Cámara Martínez intercede por Vaca de Guzmán para solicitar la licencia de impresión del tercer volumen de la obra, es decir, del primer tomo del Suplemento de los viajes de Enrique Wanton al país de las monas, que es creación original del autor español. La licencia fue aprobada por Flores, en nombre de la Academia, el 25 de octubre de dicho año ${ }^{44}$. El revisor encargado de evaluar el texto fue Juan José López de Sedano, académico de la Real Academia de la Historia y reconocida figura literaria de la época. Además de dramaturgo e historiador, López de Sedano fue editor de El Belianís Literario (1765), periódico crítico de corta vida que censuraba otras publicaciones periódicas, y del Parnaso español (1768-1778), antología en nueve volúmenes de la poesía española entre los siglos XVI y XVIII ${ }^{45}$. En este sentido, su examen de la obra de Vaca de Guzmán adquiere un valor significativo. López de Sedano celebra la superioridad literaria del texto español en comparación con el original italiano y la maestría de Vaca de Guzmán para mantener, en su continuación de la historia, el contexto ficcional en el que se desarrolla la narración de Seriman. Además, valora positivamente la calidad de la sátira en contra de los males que aquejan al mundo en general:

Habiendo examinado con toda reflexión el libro intitulado Suplemento, o sea tomo tercero de los Viajes de Enrique Wanton al país de las monas, en donde se expresan las costumbres, carácter, ciencias y policía de estos extraordinarios habitantes,

42. Archivo Histórico Nacional, Consejos, legajo 5570, expediente 46, licencia de impresión del segundo tomo de los Viajes de Enrique Wanton. Madrid, 12 de febrero de 1771. Otro documento en el que se solicita la licencia de reimpresión para los dos primeros tomos se encuentra en Consejos, legajo 50672, Madrid, 4 de mayo de 1778.

43. Real Academia de la Historia, Ms. 11/8013, n. ${ }^{\circ}$ 47, revisión de los Viajes de Enrique Wanton. Madrid, 12 de febrero de 1771, fol. 3 r.

44. Archivo Histórico Nacional, Consejos, legajo 5570, expediente 46, licencia de impresión del tercer tomo de los Viajes de Enrique Wanton. Madrid, 25 de octubre de 1777. Un documento adicional sobre la publicación de este volumen puede ser consultado en Consejos, legajo 50673, Madrid, 21 de marzo de 1782 .

45. Para más detalles sobre la obra de Juan José López de Sedano, ver Aguilar PIÑal. Bibliografía de autores españoles..., 1989, vol. V, pp. 219-223. 
ordenado y dado a luz de unos antiguos manuscritos ingleses por don Joaquín de Guzmán y Manrique, encuentro desempeñado con igual y aun mayor felicidad que en la traducción de los dos tomos antecedentes el pensamiento que se propuso el autor original de esta obra, siguiendo el mismo rumbo, no ya como traductor, sino originalmente (aunque supone, para continuar el disfraz de la idea, que lo traslada de ciertos antiguos manuscritos ingleses) con una delicada, ingeniosa y erudita invectiva contra los vicios civiles y literarios que abundan en todos los países y naciones; y en la aplicación está manejada con mucha delicadeza, artificio, decoro, decencia y juiciosa crítica. Por lo que, siendo del agrado de Vuestra Señoría Ilustrísima y habiendo aprobado los dos tomos anteriores, no encuentro dificultad por donde no se le deba conceder la misma licencia al presente ${ }^{46}$.

Al año siguiente, De la Cámara Martínez solicita el permiso para la impresión del cuarto volumen de la obra, señalando que el texto había sido considerado muy extenso, por lo que tuvo que ser enmendado en la parte inicial y en la final. El nuevo tomo es revisado igualmente por López de Sedano, quien en su informe declara que originalmente Vaca de Guzmán había planeado publicar el Suplemento en un solo volumen, pero, dada la extensión del producto final, decidió dividirlo en dos tomos:

[H]abiendo considerado su autor, don Joaquín de Guzmán y Manrique, que aquel tomo saldría en la prensa muy abultado y disconforme con los dos antecedentes, determinó dividirle en tercero y cuarto para su mejor uso y regularidad, dando a la prensa el $3 .^{\circ}$ y añadiendo al presente alguna materia, que es la que he tenido que examinar nuevamente ${ }^{47}$.

El censor reitera la habilidad estilística del autor para trasladar la crítica de costumbres de la sociedad de la época a la ficción de su relato:

[E]n lo cual encuentro el mismo mérito que en todo lo demás, así por lo delicado, oportuno y juicioso de la crítica de los vicios y abusos que se propone por objeto en la continuación de la ingeniosa invectiva de su Viaje, como por el no menos ingenioso artificio con que enlaza y ordena los acaecimientos de su ficción para deducir la censura y corrección de las costumbres viciosas y de los más comunes abusos que reinan generalmente en todo género de gentes ${ }^{48}$.

La censura previa incluía criterios como la utilidad y la instrucción que la obra podía ofrecer con miras a la formación tanto de una opinión pública culta como de un discurso catalizador de los intereses del Consejo de Castilla ${ }^{49}$. No obstante,

46. Real Academia de la Historia, Ms. 11/8016, n. ${ }^{\circ} 23$, censura del tercer tomo de los Viajes de Enrique Wanton. Madrid, 24 de octubre de 1777, fol. 2r.

47. Real Academia de la Historia, Ms. 11/8016, n. ${ }^{\circ}$ 53, censura del cuarto tomo de los Viajes de Enrique Wanton. Madrid, 13 de noviembre de 1778, fol. 2r.

48. Ibid., fols. 2r.-2v.

49. Velasco. "Las censuras...", p. 116. 
el principio fundamental era "la supervisión de la tríada clásica: las regalías, las buenas costumbres y la religión ${ }^{50}$. En efecto, el aspecto que recibe especial énfasis en la censura del Suplemento es la falta de discrepancia ideológica del texto con los intereses teológicos de la Iglesia católica y los poderes económicos del Estado español:

Por cuya vitalidad y por la ventaja de la pureza y elegancia de su estilo, me parece esta obra muy digna de la luz pública y del aplauso con que se han recibido los tomos antecedentes: sobre la principal calidad de no contener proposición alguna contraria a la fe, a la pureza de la religión, ni a las regalías ${ }^{51}$.

La licencia del cuarto volumen fue autorizada por Flores el 4 de diciembre de $1778^{52}$. Esta evidencia confirma el error de imprenta que se produjo en las copias de dicho tomo correspondientes a 1771.

Prueba de la popularidad de los Viajes son las continuas peticiones solicitando nuevas licencias de impresión para publicar más ediciones de la obra. La edición completa de los cuatro tomos es llevada a cabo por el célebre impresor Antonio de Sancha en 1778. Se concede la licencia de reimpresión de los cuatro volúmenes en $1781^{53}$. Asimismo, en 1782, Vaca de Guzmán recibe el privilegio exclusivo de reimpresión y venta de su obra hasta por diez años ${ }^{54}$, el cual es prorrogado por diez años más en $1792^{55}$. Este privilegio evidentemente incrementaría la reproducción del texto, pero también las ganancias del autor. La importancia y aceptación que había alcanzado la obra quedan demostradas con la edición que preparó la Imprenta Real en 1800. Incluso posteriormente, en 1830, el procurador Salustiano Manuel González pidió la licencia para reimprimir la copia de la obra que había adquirido gracias a su esposa Josefa Poveda ${ }^{56}$, a cuyo difunto primer marido, el librero Gabriel Gómez, Vaca de Guzmán vendió en 1800 -cuatro años antes de la muerte del autor de los Viajes- los derechos para reimprimir hasta tres veces los cuatros tomos y las láminas contenidas en ellos a cambio de tres mil reales de vellón y seis ejemplares encuadernados luego de haber transcurrido

50. Ibid.

51. Real Academia de la Historia, Ms. 11/8016, n. ${ }^{\circ}$ 53, censura del cuarto tomo..., fol. $2 \mathrm{v}$.

52. Archivo Histórico Nacional, Consejos, legajo 5570, expediente 46, licencia de impresión del cuarto tomo de los Viajes de Enrique Wanton. Madrid, 4 de diciembre de 1778.

53. Archivo Histórico Nacional, Consejos, legajo 5570, expediente 46, licencia de reimpresión de los cuatro tomos de los Viajes de Enrique Wanton. Madrid, 17 de noviembre de 1781.

54. Archivo Histórico Nacional, Consejos, legajo 5570, expediente 46, privilegio de reimpresión de los Viajes de Enrique Wanton. Madrid, 28 de enero de 1782.

55. Archivo Histórico Nacional, Consejos, legajo 5570, expediente 46, prórroga del privilegio de reimpresión de los Viajes de Enrique Wanton. Madrid, 13 de abril de 1792.

56. Archivo Histórico Nacional, Consejos, legajo 5570, expediente 46, licencia de reimpresión de los cuatro tomos de los Viajes de Enrique Wanton solicitada por Salustiano González. Madrid, 1 de diciembre de 1830 . 
dos meses desde la publicación de cada una de las tres reimpresiones ${ }^{57}$. Aparentemente, Gómez pudo reimprimir la obra solo una vez. Su edición, además, incluía las nuevas ilustraciones hechas por Miguel Gamborino, referidas anteriormente ${ }^{58}$.

Otro aspecto que revela la entusiasta valoración de los Viajes por parte de los censores es el hecho de que su cuidado y refinado uso del idioma superaba notablemente al de la traducción española de la obra que les sirvió de inspiración, Los viajes de Gulliver. Si bien, según el informe de censura del primer volumen de la obra de Swift traducida del francés al español por Ramón Máximo Spartal, no se encuentra «en su contenido cosa que se oponga a la religión, regalías y buenas costumbres, antes siendo su lectura amena y de instrucción "59, tal como sucede también con la apreciación crítica sobre el trabajo de Vaca de Guzmán, la traducción del segundo volumen del texto hecha por Spartal no fue calificada muy favorablemente en cuanto a sus cualidades lingüísticas ${ }^{60}$. El bibliotecario e historiador Miguel de Manuel, quien fue el revisor del primer tomo en 1793, condena «la impropiedad y poco esmero de la traducción. Y como de permitir estos descuidos y sandeces se han originado en estos días infinitos perjuicios a la pureza de nuestra lengua que en algunos libros parece que se habla en jerigonza, y no en castellano" ${ }^{61}$. Por tanto, exige que Spartal corrija los defectos de su mala traducción y que «lo vuelva a presentar en lenguaje puro castellano, pues siendo un libro que por sus circunstancias de entretenido y divertido puede hacerse más común que otros, resultaría por lo mismo que podrá más fácilmente infestar con la corrupción de sus frases el vulgo del pueblo español ${ }^{62}$. Cabe destacar que los textos de Swift fueron compuestos en una época en la que en Europa los impresores, los libreros y los libros mismos eran el blanco de la censura de los Gobiernos debido al carácter invariablemente anónimo de cualquier escrito difamatorio ${ }^{63}$, aspecto precisamente ejemplificado por la aparición anónima de Los viajes de Gulliver. La naturaleza controvertida de la producción textual de Swift, en particular la incisiva crítica social, política, cultural y religiosa de Los viajes de Gulliver, provocó, lógicamente, diversas reacciones

57. Archivo Histórico Nacional, Consejos, legajo 5570, expediente 46, permiso de reimpresión de los Viajes de Enrique Wanton concedido por Gutierre Vaca de Guzmán a Gabriel Gómez. Madrid, 8 de marzo de 1800 .

58. Ver la nota 31 del presente artículo.

59. Archivo Histórico Nacional, Consejos, legajo 5559, expediente 69, licencia de impresión del primer tomo de los Viajes del capitán Lemuel Gulliver a diversos países remotos. Madrid, 16 de julio de 1793

60. Ver DeACON. "La novela inglesa en la España del siglo XVIII...", p. 133.

61. Archivo Histórico Nacional, Consejos, legajo 5559, expediente 69, licencia de impresión del segundo tomo de los Viajes del capitán Lemuel Gulliver a diversos países remotos. Madrid, 18 de diciembre de 1793 .

62. Ibid.

63. Higgins, Ian. "Censorship, Libel and Self-Censorship». En Bullard, Paddy y McLaverTy, James (eds.). Jonathan Swift and the Eighteenth-Century Book. Cambridge, Reino Unido: Cambridge University Press, 2013, pp. 179-198 (p. 180). 
censoras por parte de las autoridades. A pesar de ser una aguda sátira de la sociedad inglesa de la época y de la condición humana, Los viajes de Gulliver se convirtieron en una obra emblemática de la literatura infantil y juvenil debido a que el texto es primordialmente una historia de aventuras que estimula la imaginación y curiosidad de niños y jóvenes al confrontarlos con un mundo remoto y extraño, muy diferente del mundo real. Mientras que las ediciones dieciochescas de la obra se publicaron sin alteraciones del manuscrito original, la supresión o simplificación de episodios considerados inapropiados e irreverentes para una audiencia joven se produjo en el marco de los ideales conservadores del siglo XIX ${ }^{64}$. En cuanto a las adaptaciones de Seriman y Vaca de Guzmán, parece que estas no llegaron a reconfigurarse textualmente en función de su impacto sobre la juventud lectora de sus respectivos contextos nacionales.

Es importante mencionar que la documentación de censura examinada permite perfilar ciertos detalles de la carrera burocrática de Vaca de Guzmán. Dado que era doctor en Derecho, se desempeñó como juez de cuartel y alcalde del crimen de la Real Cancillería de Granada, además de haber sido Censor de la Sociedad Económica de Granada ${ }^{65}$. Asimismo, fue ministro del Consejo Supremo de Castilla y del de la Inquisición. Su último cargo antes de morir fue el de alcalde de la Real Casa y Corte de Madrid ${ }^{66}$. Haber ocupado diversos puestos gubernamentales posibilitó que Vaca de Guzmán tuviera la oportunidad no solo de ascender en su carrera civil, sino también de poder observar de cerca el comportamiento de la sociedad española y diagnosticar sus males. Más aún, su estancia en Madrid debió de haber representado la oportunidad de tener acceso a recursos que ayudaran a promocionar su obra de manera eficaz.

\section{El ÉXITO EDITORIAL De los VIAJES}

La censura de los cuatro volúmenes de los Viajes, es decir, de la traducción de los dos tomos de Seriman y de los dos nuevos volúmenes redactados por Vaca de Guzmán, evidencia los méritos literarios, lingüísticos, didácticos y morales de la labor de traducción y creación llevada a cabo por el autor español. La obra sobre todo confirma, como pensaba el censor Martín Martínez, que España no tenía nada que envidiar a otras naciones en cuanto a la gracia del idioma, la fuerza creativa o el vigor de la imaginación. Asimismo, los resultados de la inspección de la obra dejan entrever la postura favorable adoptada por las autoridades censoras hacia un recurso discursivo tan complejo y polémico como

64. Karolides, Nicholas J. Banned Books: Literature Suppressed on Political Grounds. Nueva York: Facts On File, 2006, p. 208.

65. Aguilar Piñal. Bibliografía de autores españoles..., vol. VIII, p. 237.

66. El anuncio de la muerte de Vaca de Guzmán y una breve reseña de los cargos que desempeñó pueden verse en Gaceta de Madrid, n. ${ }^{\circ}$ 9, 29 de enero de 1805, pp. 93-104 (p. 100) 
la sátira. Según Lucienne Domergue, los censores no solían estar de acuerdo en cuanto a la apreciación y valoración de la sátira en el proceso de revisión de textos. Para López de Sedano, por ejemplo, la sátira constituía una herramienta ideológica poderosa en tanto que ayudaba a corregir las imperfecciones de la sociedad. La definía de la siguiente manera:

[E]specie sobre todas noble, útil y aplaudida entre todas las naciones cultas, cuando se ciñe y reduce en sus términos, y con propiedad se llaman sermones y tratan de la corrección de los abusos o vicios políticos o morales en general sin herir en determinados objetos ${ }^{67}$.

López de Sedano se refiere a que la modalidad de sátira que se valora es aquella que cuestiona el comportamiento social en su conjunto, no la que critica directamente a individuos específicos de la sociedad, en especial a personalidades públicas. De hecho, la crítica ad hominem era una prohibición común en el contexto de entonces. Como señala Domergue, lo que se aplaude es la imitación de la sátira clásica, es decir, de aquella forma de sátira que conlleva una intención constructiva y moralizante, tal como la definía Horacio ${ }^{68}$.

En líneas generales, la obra de Vaca de Guzmán se ajusta satisfactoriamente a los criterios de aprobación de la política de la época en cuanto a la censura de impresos. A pesar de que los escritos satíricos eran celosamente escudriñados en tanto representaban potenciales ataques al sistema vigente, el contenido de los Viajes no solo no significaba ningún peligro en el ámbito religioso o político, sino que era juzgado como útil y edificante. En una época como la Ilustración, la utilidad de los textos era un criterio determinante en la evaluación de los manuscritos que solicitaban licencias de impresión. Como señala Eva Velasco,

un escrito o impreso inútil era [...] aquel que usaba un mal método, adolecía de falta de claridad, empleaba un estilo inadecuado, no añadía elementos nuevos al conocimiento (observaciones o descubrimientos), introducía especies vanas o supersticiosas y, por último, el que cuestionaba las reglas de la crítica ${ }^{69}$.

A diferencia de las escuelas y universidades que fomentaban una instrucción puramente académica, los libros podían tener un impacto concreto en la educación del público. De este modo, la utilidad ilustrada promovía la participación de mecanismos prácticos que aseguraran la felicidad pública, la estabilidad social y el bienestar de cada uno de los habitantes de la sociedad.

Otro factor que explicaría la afición de los lectores por la obra de Vaca de Guzmán es el carácter multigenérico de su narración, la cual oscila entre la novela,

67. Citado en DOMERgue, Lucienne. La Censure des livres en Espagne à la fin de l'Ancien Régime. Madrid: Casa de Velázquez, 1996, p. 63.

68. Ibid.

69. VelasCo. "Fundamentos históricos...", pp. 129-130. 
el cuadro de costumbres, el viaje imaginario y el relato utópico. La evolución de los personajes de Enrique y Roberto a lo largo de la historia, lo que otorga a los Viajes un cariz novelístico ${ }^{70}$, provee al texto de una amenidad que no es común en el modelo tradicional de la narrativa utópica. Lo usual en las utopías es que el visitante del país utópico interactúe muy mínimamente con los habitantes del territorio que va a ser explorado. El viajero no participa activamente en la dinámica del sistema sociopolítico del lugar que visita, pues es más bien un mero observador o testigo cuya forma de pensar no se espera que cambie o evolucione en el contexto de la narración. Sin embargo, Enrique y Roberto no son compatibles con el rol pasivo que suele tener el visitante del país utópico.

En conjunción con las virtudes formales y de contenido que estructuran la obra, el hecho de que el texto haya sido resultado de un proceso de traducción e interpretación aporta una perspectiva importante para comprender el éxito que alcanzaron los Viajes entre el público lector. La tarea de traducción en el siglo XVIII no solo implicaba una labor de creación en sí misma, sino que los traductores trabajaban con un objetivo específico en mente. La traducción textual ciertamente respondía al creciente desarrollo intercultural en Europa, pero podría ser entendida también como un instrumento al servicio de la intención que pudiera haber tenido el traductor de manipular el texto extranjero original. Siguiendo la tipología de traducciones en la España dieciochesca propuesta por Inmaculada Urzainqui ${ }^{71}$, los objetivos que se trazó Vaca de Guzmán al realizar su traducción fueron los de selección, nacionalización y continuación: el autor español seleccionó las partes de la obra original que le interesaba traducir, optando por ignorar la traducción de los dos últimos volúmenes escritos por Seriman con la finalidad de poder crear su propia continuación de la historia. Aparentemente, su proceder estuvo motivado por el deseo de adaptar la obra al contexto nacional español y lograr así que los lectores se identificaran con la historia y los personajes. Vaca de Guzmán, por ejemplo, justifica su alteración de ciertas expresiones lingüísticas que, según su punto de vista, resultan válidas solo en el contexto italiano:

El curioso que haga cotejo entre la obra y la traducción hallará una u otra cosa omitida, y acaso alguna página entera; porque si el traductor italiano por contemporizar separó (según dice) del original inglés muchas expresiones que no podría

70. Sobre la concepción de los Viajes como novela, ver Álvarez BARRIENTOS, Joaquín. «Sobre utopías y viajes imaginarios: Gutierre Joaquín Vaca de Guzmán». En FuENTE, Ricardo de la (ed.). Historia de la literatura española. Madrid: Júcar, 1991, vol. XXVIII: La novela del siglo XVIII, pp. 131-141 (pp. 140-141).

71. URZAINQUI, Inmaculada. "Hacia una tipología de la traducción en el siglo XVIII: los horizontes del traductor». En DONAIRE, María Luisa y LAFARGA, Francisco (eds.). Traducción y adaptación cultural: España-Francia. Oviedo: Universidad de Oviedo, 1991, pp. 623-638 (p. 624). 
tolerar el genio de su nación, a nuestro delicado paladar desazonarían, tal vez, otras que él dejó esparcidas ${ }^{72}$.

La inclusión de láminas para ilustrar momentos importantes de la historia hacía la lectura de los Viajes más atractiva y entretenida. Al parecer, los lectores sentían cierta fascinación por la funcionalidad de las ilustraciones, tal como lo demuestra el comentario de un ávido lector de la obra aparecido en un número del Diario de Madrid en 1799. Esta persona sugiere al editor del periódico que debería publicarse una nueva edición de los Viajes mejorando los grabados que habían sido hasta ese entonces utilizados en las ediciones de los volúmenes hechas por Antonio de Sancha y que habían sido creados por José Patiño:

Señor Diarista, muy señor mío: habiendo visto las gallardas y cómodas ediciones nuevamente publicadas del Quijote, Quevedo, Solís, Gil Blas y otras, he extrañado, y aun sentido, no haya tenido ya igual fortuna la de los Viajes de Henrique [sic] Wanton al País de las Monas, cuya singular y bien formada crítica no suministra menos materia a unas hermosas y mejor grabadas láminas que las que tenemos en la impresión de dicha obra de casa de Sancha, lo que comunico a Vuestra Merced a fin de que, si estima por conveniente dar lugar en su periódico a este mi pensamiento, llegue a noticia de algún curioso que le ponga en ejecución, reimprimiendo dicha obra de los Viajes de Wanton, la que no dejará de ser bien recibida de las personas de gusto $^{73}$.

Probablemente, el pedido de este lector dio lugar a la edición de la obra, mencionada anteriormente, que publicó la Imprenta Real en 1800 con nuevas láminas hechas por Miguel Gamborino. De hecho, los dos tomos originales del Suplemento que fueron ilustrados por José Patiño contenían solo dos láminas cada uno. Coincidentemente, la traducción española de Los viajes de Gulliver contenía también dos ilustraciones en cada uno de los tres volúmenes que aparecieron en 1793, 1798 y 1800 respectivamente.

Dentro del selecto grupo de textos que conformaron el reducido corpus de la narrativa utópica en la España del siglo XVIII ${ }^{74}$, la obra de Vaca de Guzmán se consagró como un best seller gracias no solo a la originalidad de su composición textual, sino también al calculado manejo editorial que puso en práctica su autor durante el proceso de publicación. La historia de los viajes de Enrique Wanton posee una trascendencia sociopolítica, cultural y nacional que está ausente en otros textos de la tradición utópica de la España ilustrada, tales como el relato

72. [VACA] DE GuZmán y Manrique, [Gutierre] Joaquín. «Prólogo». En Seriman, Zaccaria. Viajes de Enrique Wanton al país de las monas. Trad. [Gutierre] Joaquín [Vaca] de Guzmán y Manrique. Alcalá: Imprenta de María García Briones, 1769, vol. I, pp. iii-vi (pp. v-vi).

73. Diario de Madrid, n. ${ }^{\circ}$ 79, 20 de marzo de 1799, pp. 321-234 (p. 322).

74. Ver Álvarez de Miranda, Pedro. "Los libros de viajes y las utopías en el XVIII español». En García de la Concha, Víctor (ed.). Historia de la literatura española. Madrid: Espasa-Calpe, 1995, vol. VII: CARNero, Guillermo (ed.). Siglo XVIII (II), pp. 682-706. 
anónimo de la utopía de los Ayparchontes (1784-1785) la Monarquía columbina (pre-1787) de Andrés Merino de Jesucristo ${ }^{76}$, la narración anónima de la sociedad utópica de Zenit $(1787)^{77}$, la historia contada por Manuel Rubín de Celis de otra sociedad ideal imaginaria que algunos críticos han convenido en llamar "La isla» $(1787)^{78}$, la "Aventura magna del Bachiller» (1790) de Pedro Gatell i Carnicer ${ }^{79}$, el cuento utópico conocido como "Cartas de Mariano a Antonio» (1798) en El Evangelio en triunfo de Pablo de Olavide y Jáuregui ${ }^{80}$ y el Viaje de un filósofo a Selenópolis (1804) de Antonio Marqués y Espejo ${ }^{81}$. Resulta incluso sintomático que, habiendo sido la prensa periódica un medio importante para la difusión de la narrativa utópica en la España de las Luces, el trabajo de Vaca de Guzmán haya motivado la creación en 1833 de un periódico mexicano llamado El Mono, en el cual se reproducían diálogos jocosos entre diversos personajes, uno de los cuales era Enrique Wanton, quien decía ser el asesor de los editores del periódico ${ }^{82}$. Esta compleja utopía española parece, pues, haber logrado cierta resonancia extranacional y extendido su éxito hasta mucho tiempo después de haber salido de la imprenta por primera vez.

\section{CONCLUSIÓN}

Los Viajes de Enrique Wanton al país de las monas y su respectivo Suplemento conforman un sofisticado material literario que recrea críticamente las circunstancias sociales y culturales de la sociedad española que urgen ser reformuladas. Superando la virtud literaria de la obra original italiana que le sirvió de base, la propuesta central de Vaca de Guzmán es la implementación de una utopía de

75. El Censor. Ed. José Miguel Caso González. Oviedo: Universidad de Oviedo, Instituto Feijoo de Estudios del Siglo XVIII, 1989, pp. 131-150, 225-239, 257-270.

76. Álvarez de Miranda, Pedro (ed.). Tratado sobre la monarquía columbina: una utopía antiilustrada del siglo XVIII. Madrid: El Archipiélago, 1980, pp. 1-29.

77. Correo de Madrid, n. ${ }^{\circ}$ 57, 9 de mayo de 1787, pp. 241-244; n. ${ }^{\circ}$ 58, 12 de mayo de 1787, pp. 245-248; n. ${ }^{\circ}$ 59, 16 de mayo de 1787, pp. 249-252; n. ${ }^{\circ}$ 60, 19 de mayo de 1787, pp. 253-256.

78. Rubín de Celis, Manuel. El Corresponsal del Censor. Ed. Klaus-Dieter Ertler, Renate Hodab e Inmaculada Urzainqui. Madrid: Iberoamericana; Frankfurt am Main: Vervuert, 2009, pp. 165-175.

79. Gatell i Carnicer, Pedro. El Argonauta Español: Periódico Gaditano. Ed. Marieta Cantos Casenave y María José Rodríguez Sánchez de León. Sevilla: Renacimiento, 2008, pp. 210-213.

80. Dufour, Gérard (ed.). Cartas de Mariano a Antonio: el programa ilustrado de El Evangelio en triunfo. Aix-en-Provence: Université de Provence, 1988, pp. 37-229.

81. [MARQués y ESPEjO, Antonio]. Viaje de un filósofo a Selenópolis, corte desconocida de los habitantes de la Tierra. Madrid: Gómez Fuentenebro, 1804. El texto es una traducción adaptada de Le Voyageur philosophe dans un pays inconnu aux habitants de la Terre (El viajero filósofo en un país desconocido para los habitantes de la Tierra), obra publicada en 1761 por Daniel Villeneuve.

82. CASTRO, Miguel Ángel y CurIEL, Guadalupe (eds.). Publicaciones periódicas mexicanas del siglo XIX, 1822-1855: fondo antiguo de la Hemeroteca Nacional y fondo reservado de la Biblioteca Nacional de México. Ciudad de México: Universidad Nacional Autónoma de México, 2000, p. 265. 
integración nacional que contrarreste la práctica del comportamiento cosmopolita que socava la esencia de la idiosincrasia española. Más específicamente, la concepción de una utopía periférica o provinciana surge como una solución efectiva ante los efectos alienantes que una utopía eminentemente urbana o metropolitana puede ocasionar. Ante este contexto, el lector es convocado a suscribir el plan del autor sevillano sobre cómo lograr que se tome conciencia en cuanto a la importancia de la autoidentificación con el territorio y la cultura propios. El aparato de censura en torno de la obra demuestra cuán útil resultaba saber moldear el gusto literario y la reacción ideológica de la audiencia con el fin de instruirla y entretenerla. La obra de Vaca de Guzmán constituye, en última instancia, una invectiva didáctica y deleitable que terminó por forjar su propio camino hacia el éxito literario y comercial ${ }^{83}$.

\section{Bibliografía}

Aguilar Piñal, Francisco. Bibliografía de autores españoles del siglo XVIII. Madrid: Consejo Superior de Investigaciones Científicas, vol. V (1989) y vol. VIII (1995).

ALMANZA-GÁLVEZ, Carla. Form and Reform in Eighteenth-Century Spain: Utopian Narratives and Socio-Political Debate. Cambridge, Reino Unido: Legenda, 2019.

ÁLVAREZ BARRIENTOS, Joaquín. «Sobre utopías y viajes imaginarios: Gutierre Joaquín Vaca de Guzmán». En FuENTE, Ricardo de la (ed.). Historia de la literatura española. Madrid: Júcar, 1991, vol. XXVIII: La novela del siglo XVIII, pp. 131-141.

Álvarez de Miranda, Pedro (ed.). Tratado sobre la monarquía columbina: una utopía antiilustrada del siglo XVIII. Madrid: El Archipiélago, 1980.

Álvarez De Miranda, Pedro. "Los libros de viajes y las utopías en el XVIII español». En GarCía DE la CONCHA, Víctor (ed.). Historia de la literatura española. Madrid: Espasa-Calpe, 1995, vol. VII: CARNERo, Guillermo (ed.). Siglo XVIII (II), pp. 682-706.

Archivo Histórico Nacional, Consejos, legajos 5559, 5570, 50662, 50672, 50673.

BAKER-Smith, Dominic. More's Utopia. Londres: HarperCollins Academic, 1991.

CAstro, Miguel Ángel y Curiel, Guadalupe (eds.). Publicaciones periódicas mexicanas del siglo XIX, 1822-1855: fondo antiguo de la Hemeroteca Nacional y fondo reservado de la Biblioteca Nacional de México. Ciudad de México: Universidad Nacional Autónoma de México, 2000.

El Censor. Ed. José Miguel Caso González. Oviedo: Universidad de Oviedo, Instituto Feijoo de Estudios del Siglo XVIII, 1989.

ClaEYs, Gregory (ed.). The Cambridge Companion to Utopian Literature. Cambridge, Reino Unido: Cambridge University Press, 2010.

83. La realización de este trabajo ha sido posible gracias a una estancia de investigación posdoctoral financiada por la Cátedra de Altos Estudios del Español de la Universidad de Salamanca. Especiales agradecimientos van dirigidos a Philip Deacon, por sus valiosas observaciones sobre este artículo; a Gabriel Sánchez Espinosa, por sugerir el estudio documental que dio origen a la presente investigación; y a María José Rodríguez Sánchez de León, por su alentador apoyo durante el desarrollo inicial del proyecto. 
LA CENSURA Y PUBLICACIÓN DE LOS VIAJES DE ENRIQUE WANTON AL PAÍS DE LAS MONAS..

Continuación del Memorial Literario, Instructivo y Curioso de la Corte de Madrid, febrero de 1794.

Correo de Madrid, n. ${ }^{\circ}$ 57, 9 de mayo de 1787; n. ${ }^{\circ}$ 58, 12 de mayo de 1787; n. ${ }^{\circ}$ 59, 16 de mayo de 1787; n. ${ }^{\circ} 60,19$ de mayo de 1787.

DeACON, Philip. «La novela inglesa en la España del siglo XVIII: fortuna y adversidades». En García Lara, Fernando (ed.). Actas del I Congreso Internacional sobre Novela del Siglo XVIII. Almería: Universidad de Almería, 1998, pp. 123-139.

Defourneaux, Marcelin. Inquisición y censura de libros en la España del siglo XVIII. Trad. José Ignacio Tellechea Idígoras. Madrid: Taurus, 1973.

Diario de Madrid, n. ${ }^{\circ}$ 79, 20 de marzo de 1799.

Domergue, Lucienne. Censure et Lumières dans l'Espagne de Charles III. París: Éditions du CNRS, 1982.

Domergue, Lucienne. La Censure des livres en Espagne à la fin de l'Ancien Régime. Madrid: Casa de Velázquez, 1996.

Dufour, Gérard (ed.). Cartas de Mariano a Antonio: el programa ilustrado de El Evangelio en triunfo. Aix-en-Provence: Université de Provence, 1988.

ELLIOTT, Robert C. The Shape of Utopia: Studies in a Literary Genre. Chicago; Londres: University of Chicago Press, 1970.

Escobar, José. «Más sobre los orígenes de civilizar y civilización en la España del siglo XVIII». Nueva Revista de Filología Hispánica, 1984, 33, pp. 88-114.

EsCOBAR, José y PERCIVAL, Anthony. «Viaje imaginario y sátira de costumbres en la España del siglo XVIII: los Viajes de Enrique Wanton al país de las monas». En HINTERHÄUSER, Hans; RÖSSNER, Michael y Wagner, Birgit (eds.). Aufstieg und Krise der Vernunft: Komparatistische Studien zur Literatur der Aufklärung und des Fin-de-Siècle. Viena: Hermann Böhlaus Nachfolger, 1984, pp. 79-94.

Gaceta de Madrid, n. ${ }^{\circ} 32,8$ de agosto de 1769; n. ${ }^{\circ} 44,29$ de octubre de 1771; n. ${ }^{\circ} 9,3$ de marzo de 1778; n. ${ }^{\circ} 35,30$ de abril de $1779 ;$ n. ${ }^{\circ}$ 9, 29 de enero de 1805.

Gatell i Carnicer, Pedro. El Argonauta Español: Periódico Gaditano. Ed. Marieta Cantos Casenave y María José Rodríguez Sánchez de León. Sevilla: Renacimiento, 2008.

Gove, Philip Babcock. The Imaginary Voyage in Prose Fiction. Londres: Holland Press, 1961.

Guinard, Paul-Jacques. La Presse espagnole de 1737 à 1791: formation et signification d'un genre. París: Centre de Recherches Hispaniques, Institut d'Études Hispaniques, 1973.

Higgins, Ian. "Censorship, Libel and Self-Censorship». En Bullard, Paddy y McLaverTy, James (eds.). Jonathan Swift and the Eighteenth-Century Book. Cambridge, Reino Unido: Cambridge University Press, 2013, pp. 179-198.

Karolides, Nicholas J. Banned Books: Literature Suppressed on Political Grounds. Nueva York: Facts On File, 2006.

LARRA, Mariano José de. "Panorama matritense". Cuadros de costumbres de la capital observados y descritos por un Curioso Parlante. Artículo segundo y último». En Pérez VIDAL, Alejandro (ed.). Fígaro: colección de artículos dramáticos, literarios, políticos y de costumbres. Barcelona: Crítica, 1997, pp. 544-548.

[MARQués y ESPejo, Antonio]. Viaje de un filósofo a Selenópolis, corte desconocida de los habitantes de la Tierra. Madrid: Gómez Fuentenebro, 1804.

Mesonero Romanos, Ramón de. Panorama matritense. Cuadros de costumbres de la capital, observados y descritos por un Curioso Parlante. Madrid: Imprenta de Repullés, 1835, vol. I. 
Mesonero Romanos, Ramón de. «Memorias de un setentón». En Seco Serrano, Carlos (ed.). Obras de Ramón de Mesonero Romanos. Madrid: Atlas, 1967, vol. V, pp. 1-247.

MONTESINOS, José F. Introducción a una bistoria de la novela en España en el siglo XIX. Valencia: Castalia, 1972.

Morange, Claude. "Variations sur un thème: le monde rural dans le Suplemento [...] de los viages de Enrique Wanton (1778)». En SERrano, Carlos; Duviols, Jean-Paul y Molinié, Annie (eds.). Les Voies des Lumières: le monde ibérique au XVIII siècle. París: Presses de l'Université de Paris-Sorbonne, 1998, pp. 79-111.

Morson, Gary Saul. The Boundaries of Genre: Dostoevsky's Diary of a Writer and the Traditions of Literary Utopia. Evanston, Illinois: Northwestern University Press, 1981.

Penrose, Mehl. "Petimetres as a Third Sex in José Clavijo y Fajardo's El pensador matritense». Dieciocho, 2009, 2, pp. 351-364.

Real Academia de la Historia, Mss. 11/8013, n. ${ }^{\circ} 47 ; 11 / 8016$, n. ${ }^{\circ} 23 ; 11 / 8016$, n. ${ }^{\circ} 53$.

Roemer, Kenneth M. Utopian Audiences: How Readers Locate Nowhere. Amherst; Boston: University of Massachusetts Press, 2003.

Rubín de Celis, Manuel. El Corresponsal del Censor. Ed. Klaus-Dieter Ertler, Renate Hodab e Inmaculada Urzainqui. Madrid: Iberoamericana; Frankfurt am Main: Vervuert, 2009.

RUMEU DE ARMAS, Antonio. Historia de la censura literaria gubernativa en España: historia, legislación, procedimientos. Madrid: M. Aguilar, 1940.

SEMPERE y GUARINOS, Juan. Ensayo de una biblioteca española de los mejores escritores del reinado de Carlos III. Madrid: Imprenta Real, 1789 (Madrid: Gredos, 1969, edición facsímil), vol. VI.

SERIMAN, Zaccaria. Viaggi di Enrico Wanton alle terre incognite australi, ed al paese delle scimmie, ne' quali si spiegano il carattere, li costumi, le scienze, e la polizia di quegli straordinari abitanti. Tradotti da un manoscritto inglese, con figure in rame. Venecia: Giovanni Tagier, 1749, 2 vols.

SERIMAN, Zaccaria. Viaggi di Enrico Wanton alle terre incognite australi, ed ai regni delle scimmie, e dei cinocefali, nuovamente tradotti da un manoscritto inglese. Berna: s. i., 1764, 2 vols.

SERIMAN, Zaccaria. Viajes de Enrique Wanton al país de las monas. Trad. [Gutierre] Joaquín [Vaca] de Guzmán y Manrique. Madrid: Imprenta de Pantaleón Aznar, 1771, vol. II.

URZAINQUI, Inmaculada. «Hacia una tipología de la traducción en el siglo XVIII: los horizontes del traductor». En Donaire, María Luisa y Lafarga, Francisco (eds.). Traducción y adaptación cultural: España-Francia. Oviedo: Universidad de Oviedo, 1991, pp. 623-638.

[VAca] De GuZMán y ManRiQue, [Gutierre] Joaquín. «Prólogo». En Seriman, Zaccaria. Viajes de Enrique Wanton al país de las monas. Trad. [Gutierre] Joaquín [Vaca] de Guzmán y Manrique. Alcalá: Imprenta de María García Briones, 1769, vol. I, pp. iii-vi.

[VACA] DE GUZMÁN y MANRIQUe, [Gutierre] Joaquín. Suplemento de los viajes de Enrique Wanton al país de las monas. Madrid: Antonio de Sancha, 1778, 2 vols.

VELASCO, Eva. "Fundamentos históricos y principios ideológicos del proyecto de reforma del sistema de censura previa en 1770». Cuadernos Dieciochistas, 2003, 4, pp. 123-134.

Velasco, Eva. «Las censuras de la Real Academia de la Historia». En Durán LóPEz, Fernando (ed.). Instituciones censoras: nuevos acercamientos a la censura de libros en la España de la Ilustración. Madrid: Consejo Superior de Investigaciones Científicas, 2016, pp. 113-158.

White, Donald Maxwell. Zaccaria Seriman (1709-1784) and the Viaggi di Enrico Wanton: A Contribution to the Study of the Enlightenment in Italy. Manchester, Reino Unido: Manchester University Press, 1961. 